\title{
The subcoronary Toronto stentless versus supra-annular Perimount stented replacement aortic valve: Early clinical and hemodynamic results of a randomized comparison in 160 patients
}

John B. Chambers, MD, FACC, Helen M. Rimington, BSc, Fiona Hodson, RGN, Ronak Rajani, MRCP, and Christopher I. Blauth, MS, FRCS

From the Valve Study Group, St Thomas Hospital, London, United Kingdom.

Funded by Research Echocardiography with an educational grant from St Jude Medical, Inc.

Received for publication Aug 1, 2005; revisions received Nov 14, 2005; accepted for publication Nov 18, 2005

Address for reprints: John Chambers, MD, FACC, Cardiothoracic Centre, St Thomas Hospital, London SE1 7EH, United Kingdom (E-mail: jboydchambers@aol.com).

J Thorac Cardiovasc Surg 2006;131:878-82

$0022-5223 / \$ 32.00$

Copyright () 2006 by The American Association for Thoracic Surgery

doi:10.1016/j.jtcvs.2005.11.021
Background: A stentless valve is expected to be hemodynamically superior to a stented valve. The aim of this study was to compare early postoperative hemodynamic function and clinical events in a randomized, prospective series of 160 stentless and stented biological replacement aortic valves.

Methods: We randomized 160 consecutive patients on 1 surgeon's list to receive either a Toronto stentless porcine valve (St Jude Medical, Inc, St Paul, Minn) or a Perimount stented bovine pericardial valve (Edwards Lifesciences, Irvine, Calif). Echocardiography was performed at discharge, between 3 and 6 months, and at 1 year after surgery. Statistical analysis was performed by both intention to treat and actual valves implanted.

Results: The mean labeled size of both designs of valve was 24.7. There were no statistically significant differences in results at any time interval or whether analysis was performed by actual valves implanted or intention to treat. At 3 to 6 months for the Toronto versus the Perimount valve, the effective orifice area was 1.58 versus $1.66 \mathrm{~cm}^{2}$, the mean pressure difference was 7.54 versus $7.42 \mathrm{~mm} \mathrm{Hg}$, and the peak velocity was 2.07 versus $2.0 .1 \mathrm{~m} / \mathrm{s}$. There was no difference in mortality, regression of left ventricular hypertrophy, or complications other than paraprosthetic regurgitation at 12 months or on follow-up for a proportion of the sample to 8 years. The incidence of regurgitation through the valves was similar for Toronto $(10 \%)$ and Perimount (13.8\%) at 1 year, but mild paraprosthetic regurgitation was found in 5 patients with the Perimount valve and none with Toronto valves.

Conclusions: There were no significant differences in hemodynamic function or clinical events between the stented and stentless biological valves chosen for comparison in the early postoperative period or in preliminary follow-up to 5 years.

A ll stented biological replacement valves are relatively obstructive compared with normal native valves. ${ }^{\text {E1 }}$ This could limit or delay regression of left ventricular (LV) hypertrophy ${ }^{\mathrm{E} 2}$ or contribute to mortality and impaired functional recovery after aortic valve surgery. An improvement in hemodynamic function is one of the main benefits expected from stentless valves. Because these lack both stents and a sewing ring, there should be a larger orifice available for flow.

In an early nonrandomized comparison using historical control data, the Toronto stentless valve was shown to be superior to a Hancock II stented porcine valve (Medtronic, Inc, Minneapolis, Minn) at every labeled size. ${ }^{\text {E3 }}$ This result was confirmed in some,${ }^{\mathrm{E} 4}$ but not all, consecutive nonrandomized studies. ${ }^{\mathrm{E} 5}$ Randomized studies also show conflicting results, some in favor of stentless valves ${ }^{\mathrm{E} 2, \mathrm{E} 6}$ and others showing no significant difference in hemodynamic function. ${ }^{\mathrm{E} 7}$ These dis- 


\section{Abbreviation and Acronym \\ $\mathrm{LV}=$ left ventricular}

crepancies may partly be caused by a failure to correct for flow. It may also be inappropriate to compare valves of the same labeled size because these may differ in actual size. ${ }^{\mathrm{E} 8}$ Furthermore, involvement of more than 1 surgeon introduces the possibility of uncontrolled procedural variability. The aim of this study was, therefore, to compare early flow-corrected hemodynamic function, LV mass regression, and clinical results in a single surgeon's series of patients prospectively randomized to either a stentless or stented valve.

\section{Methods \\ Patients}

A total of 160 consecutive patients scheduled to have single bioprosthetic valve replacement in the aortic position were randomized. The mean age was 72 years (range, $54-85$ years), and 82 $(51 \%)$ were male. The native disease necessitating operation was dominant aortic stenosis in 132, dominant regurgitation in 16, mixed disease in 5, and a failing replacement valve in 7 . Coexistent coronary bypass grafting was performed in 56, and aortic root replacement in 1 (Table 1). The first patient underwent operation on September 19, 1995, and the last did so on December 17, 2002. The study was accepted by the Local Committee on Ethical Practice, and all patients gave written consent.

\section{Surgery}

The Toronto stentless valve (St Jude Medical, Inc, St Paul, Minn) consists of a preparation of porcine aortic root sculpted to accommodate the coronary ostia and lined externally with Dacron (DuPont, Wilmington, Del). Sizing was undertaken at the sinotubular junction, as discussed by David and colleagues. ${ }^{\text {E9 }}$ Aortoplasty or enlargement of the sinotubular junction was not required. Implantation was at the level of the annulus, with the lower suture line in a circle joining the lower midpoints of previous cuspal attachment and passing across the intercommissural triangles. The porcine commissures were suspended independently, and a running polypropylene suture was used for both the lower and upper suture lines. The Perimount valve (Edwards Lifesciences Inc, Irvine, Calif) is composed of bovine pericardium mounted in a polypropylene stent with a sewing cuff. It was implanted with continuous sutures, which tended to position it in a supra-annular position.

The patients were randomized at the time of listing for operation by using a random number sequence with a block of 16 . However, 11 patients did not receive the valve assigned by randomization. Three patients randomized to a Perimount received a Toronto because of annular destruction. Eight patients randomized to a Toronto received a Perimount because of severe aortic calcification, sinotubular diameter more than $10 \%$ larger than the annulus diameter, or difficult access as a result of adhesions. As a consequence, a total of 75 patients actually received a Toronto and 85 received a Perimount valve. Sizing was performed for both
TABLE 1. Demographic comparison of patients actually receiving Toronto or Perimount valves

\begin{tabular}{lcc}
\hline Variable & $\begin{array}{c}\text { Toronto } \\
(\mathbf{n}=\mathbf{7 5})\end{array}$ & $\begin{array}{c}\text { Perimount } \\
\text { (n = 85) }\end{array}$ \\
\hline Age, y, mean (range) & $72(61-85)$ & $72(54-84)$ \\
Male/female & $38: 37$ & $44: 41$ \\
Height $(\mathrm{cm})$ & $165(10.7)$ & $166(9.5)$ \\
Weight $(\mathrm{kg})$ & $71.1(15.7)$ & $74.8(14)$ \\
BSA (kg/m $\left.{ }^{2}\right)$ & $1.78(0.23)$ & $1.82(0.19)$ \\
Etiology & & \\
Aortic stenosis & 63 & 69 \\
Aortic regurgitation & 5 & 11 \\
Mixed & 3 & 2 \\
Previous aortic valve replacement & 4 & 3 \\
Associated procedures & & \\
Coronary bypass grafts & 30 & 26 \\
Aortic root replacement & 1 & 0 \\
Preoperative NYHA class & & \\
I & 2 & 7 \\
II & 14 & 20 \\
III & 37 & 32 \\
IV & 22 & 26 \\
\hline
\end{tabular}

Data are mean (SD) unless otherwise noted. BSA, Body surface area; NYHA, New York Heart Association.

designs of valve, and the valve size that would have been implanted had the other valve been randomized was noted.

\section{Echocardiography}

Studies were performed immediately before discharge, between 3 and 6 months after surgery, and at 1 year (range, 10-14 months). Only 140 patients (66 with a Toronto and 74 with a Perimount) were studied at 3 to 6 months because 10 had died, 8 allowed follow-up only by telephone, 1 was an inpatient elsewhere, and 1 was in prison. By 1 year, there were a further 3 deaths, 10 allowed only follow-up by telephone, 4 were in hospital or prison, and 1 failed to attend, thus leaving a total of 132 patients (60 Toronto and 72 Perimount) who underwent echocardiography. Measurements were made as recommended by the American Society of Echocardiography ${ }^{\mathrm{E} 10}$ over 3 cycles in sinus rhythm or over 6 cycles in atrial fibrillation. Regurgitant jets were localized and then graded by a combination of the diameter of the base of the jet, and the density and slope of the aortic regurgitant signal were recorded by using continuous wave Doppler imaging. Moderate regurgitation was defined by a jet height between $25 \%$ and $60 \%$ of the outflow diameter with a pressure half-time longer than 400 milliseconds. Mild regurgitation was defined by a jet height less than $25 \%$ of the outflow diameter and a complete, low-intensity continuous waveform with a pressure half-time longer than 400 milliseconds. Trivial regurgitation was defined by a thin low-momentum jet ending close to the valve with an incomplete continuous waveform. No jet in this study was severe.

\section{Calculations}

The following calculations were performed: effective orifice area (EOA) was calculated by the continuity equation: 
TABLE 2. Hemodynamic function on echocardiography at 3 to 6 months and 1 year

\begin{tabular}{|c|c|c|c|c|}
\hline Variable & Toronto & Perimount & $\begin{array}{l}95 \% \mathrm{Cl} \text { of the } \\
\text { difference }\end{array}$ & $P$ value \\
\hline LVOT diameter $(\mathrm{cm})$ & $2.00(0.19)$ & $2.07(0.17)$ & $-0.13,0.12$ & .746 \\
\hline Aortic peak velocity at $1 \mathrm{y}(\mathrm{m} / \mathrm{s})$ & $2.10(0.41)$ & $2.05(0.41)$ & $-0.1,0.2$ & .539 \\
\hline Mean pressure decrease at $3-6 \mathrm{mo}(\mathrm{mm} \mathrm{Hg})$ & $7.54(3.65)$ & $7.42(3.59)$ & $-1.1,1.3$ & .850 \\
\hline Mean pressure decrease at 1 y $(\mathrm{mm} \mathrm{Hg})$ & $7.81(3.67)$ & $7.60(3.75)$ & $-1.1,1.5$ & .738 \\
\hline EOAI at $3-6 \mathrm{mo}\left(\mathrm{cm}^{2} / \mathrm{m}^{2}\right)$ & $0.89(0.26)$ & $0.90(0.26)$ & $-0.10,0.07$ & .775 \\
\hline $\mathrm{EOAl}$ at $1 \mathrm{y}\left(\mathrm{cm}^{2} / \mathrm{m}^{2}\right)$ & $0.88(0.22)$ & $0.90(0.26)$ & $-0.11,0.06$ & .537 \\
\hline
\end{tabular}

$\mathrm{Cl}$, Confidence interval; $L V O T$, left ventricular outflow tract; EOAl, effective orifice area index.

$$
\mathrm{EOA}\left(\mathrm{cm}^{2}\right)=\mathrm{CSA} \times \mathrm{VTI}_{1} / \mathrm{VTI}_{2},
$$

where CSA is the LV outflow cross-sectional area (square centimeters) calculated from the diameter. Assuming a circular cross section, $\mathrm{VTI}_{1}$ is the subaortic velocity integral (centimeters), and $\mathrm{VTI}_{2}$ is the aortic velocity integral (centimeters). The peak pressure difference $(\Delta \mathrm{P})$ across the aortic valve is

$$
\text { Peak } \Delta \mathrm{P}(\mathrm{mm} \mathrm{Hg})=4\left(\mathrm{v}_{2}^{2}-\mathrm{v}_{1}^{2}\right),
$$

where $\mathrm{v}_{2}$ is the transaortic peak velocity (meters per second) and $\mathrm{v}_{1}$ is the subaortic peak velocity (meters per second). The mean $\Delta \mathrm{P}$ across the aortic valve is

$$
\text { Mean } \Delta \mathrm{P}(\mathrm{mm} \mathrm{Hg})=\text { aortic mean } \Delta \mathrm{P}-\text { subaortic mean } \Delta \mathrm{P},
$$

and

$$
\mathrm{LV} \text { mass }(\mathrm{g})=0.83(\mathrm{LVDD}+\mathrm{IVS}+\mathrm{PW})^{3}-\mathrm{LVDD}^{3}+0.6 \text {, }
$$

where LVDD is LV diastolic diameter, IVS is interventricular septum; and $\mathrm{PW}$ is posterior wall.

Effective orifice area and LV mass were both indexed to body-surface area. Thresholds for LV hypertrophy by using this method are $134 \mathrm{~g} / \mathrm{m}^{2}$ for men and $110 \mathrm{~g} / \mathrm{m}^{2}$ for women. ${ }^{\mathrm{E} 11}$

\section{Clinical Events}

Patients were interviewed at their 3- to 6-month and 1-year visits. The definitions used were as recommended by The Society of Thoracic Surgeons/The American Association for Thoracic Surgery guidelines. ${ }^{\mathrm{E} 22}$ If the exact timing of an event was not known, it was taken as perioperative if noted at the immediate postoperative visit. It was recorded as at the midpoint between 2 visits if absent at the first and present at the second. Dysrhythmic deaths after recovery from the anesthetic but before discharge were included as valve related. Dysrhythmias after surgery were not included as complications if already apparent before surgery.

\section{Analysis}

The mean and standard deviation values were calculated for variables that were normally distributed and as the median and range for those that were skewed. Clinical events were expressed as a proportion of the entire population, whereas the incidence of regurgitation was expressed as a proportion of those having echocardiograms. Comparisons were made between valve types by using the unpaired $t$ test or nonparametric Mann-Whitney $U$ test as appropriate, with analyses both by intention to treat and actual valves implanted. The 2 valve types were also compared on changes between successive studies. The incidence of regurgitation was compared by using the Fisher exact test. Analyses were performed with the SPSS version 11.5.1 for Windows (SPSS Inc, Chicago, Ill).

\section{Results}

\section{General and Hemodynamic Data}

Demographic characteristics in the 2 groups were similar (Table 1). The mean size implanted in the Toronto group was 24.7 (SD, 2.69), and the mean size of Toronto that would have been implanted in the Perimount group was also 24.7 (SD, 2.09). Similarly, the mean size implanted in the Perimount group was 24.7 (SD, 2.17), and the mean Perimount that would have been implanted in the Toronto group was 24.8 (SD, 2.51). The hemodynamic results for each valve type actually implanted according to label size at 3 to 6 months are given in Tables E1 and E2, and those at 1 year are given in Tables E3 and E4.

Results were similar whether analyzed by intention to treat or actual valves implanted. They were also similar whether predischarge, 3- to 6-month, or 1-year results were used. For this reason, 95\% confidence intervals and $P$ values are given only for the actual treatment comparison at 3 to 6 months and 1 year (Table 2). There were no significant differences in any hemodynamic measurements.

The incidence of regurgitation through the valve at 3 to 6 months was $3(5 \%)$ for the Toronto and $6(8.3 \%)$ for the Perimount (Figure e1). There were no statistically significant differences between the groups in the incidence of regurgitation at 3 to 6 months or 1 year. There was paraprosthetic regurgitation in $5(7 \%)$ of the surviving Perimount group and none with Toronto valves. 


\section{Function and Mass}

There was a decrease in the LV mass index at 3 to 6 months for the Toronto by a mean of $6.7 \%$, from $224 \mathrm{~g} / \mathrm{m}^{2}\left(79 \mathrm{~g} / \mathrm{m}^{2}\right)$ to $188 \mathrm{~g} / \mathrm{m}^{2}\left(85 \mathrm{~g} / \mathrm{m}^{2}\right)$. For the Perimount, there was a decrease by a mean of $12 \%$, from $249 \mathrm{~g} / \mathrm{m}^{2}\left(76 \mathrm{~g} / \mathrm{m}^{2}\right)$ to 199 $\mathrm{g} / \mathrm{m}^{2}\left(62 \mathrm{~g} / \mathrm{m}^{2} ; P=.43\right)$. At 1 year, there was a decrease from preoperative values by $11 \%$, to $177 \mathrm{~g} / \mathrm{m}^{2}\left(75 \mathrm{~g} / \mathrm{m}^{2}\right)$ for the Toronto, and $20 \%$, to $182 \mathrm{~g} / \mathrm{m}^{2}\left(57 \mathrm{~g} / \mathrm{m}^{2}\right)$, for the Perimount group $(P=.21)$. There were no differences in the 2 valve types in terms of LV diastolic diameter or fractional shortening.

\section{Clinical Events}

There were 7 (4.4\%) deaths before 30 days and 13 (8.1\%) deaths in total in the first year (Table E5). There was no statistically significant difference between the 2 valve types. There were $9(5.6 \%)$ early complications, 6 cerebrovascular events ( 3 in each group), 2 gastrointestinal bleeds ( 1 in each group), and 1 paraprosthetic regurgitation in the Perimount group. There were $15(9.4 \%)$ complications between 30 days and 1 year, 8 cerebrovascular events ( 4 in each group), 1 gastrointestinal bleed in the Perimount group, 4 paraprosthetic leaks in the Perimount group, an acquired ventricular septal defect in the Perimount group, and a fistula between the aorta and right atrium in the Toronto group. The 4 paraprosthetic regurgitant jets and the ventricular septal defect were not noted on the predischarge studies, although these were of suboptimal image quality. There were no statistically significant differences in the incidence of death or nonfatal complications up to 5 years. Between 1 and 5 years, there were 6 deaths and 4 nonfatal complications in both groups.

\section{Discussion}

In the absence of a stent and sewing ring, there should be more space available for flow in a stentless valve. It is therefore expected to be hemodynamically superior to an equivalent stented valve intended for implantation in a patient annulus of the same diameter. However, this study showed no significant hemodynamic difference between the stentless Toronto and the stented Perimount valve in a randomized comparison in 160 patients.

\section{Previous Work}

An early case-controlled study showed significant differences between the Toronto stentless and Hancock II stented porcine valve at every labeled size. ${ }^{\mathrm{E} 3}$ These results were confirmed in small nonrandomized studies ${ }^{\mathrm{E} 13, \mathrm{E} 14}$ and in another larger nonrandomized study ${ }^{\mathrm{E} 4}$ in which the mean effective orifice area for 36 stentless Toronto valves was 1.9 $\mathrm{cm}^{2}$, compared with $1.5 \mathrm{~cm}^{2}$ for 23 Carpentier-Edwards or Hancock II stented porcine valves. However, these results must be interpreted carefully because the labeled size may differ from the diameter of the patient tissue annulus. ${ }^{\mathrm{E} 8} \mathrm{It}$ may, therefore, be inappropriate to compare valves of the same labeled size if they are of different design.

Randomization should avoid this problem because the comparison is then made by using the patient rather than the labeled size as the standard. A prospective randomized study ${ }^{\mathrm{E} 6}$ compared the stented porcine Carpentier-Edwards valve with either the Toronto or Freestyle stentless valve. The peak transaortic peak velocity was $2.3 \mathrm{~m} / \mathrm{s}$ in the stentless and $2.5 \mathrm{~m} / \mathrm{s}$ in the stented valves after surgery. By 6 months, these figures were 2.2 and $2.4 \mathrm{~m} / \mathrm{s}$, respectively. The difference was not statistically significant immediately after surgery, but it was at 6 months. Another randomized comparison $^{\mathrm{E} 7}$ of stentless (Toronto or Biocor) and stented (Hancock II) valves showed a statistically nonsignificant trend in favor of the stentless valves. However, neither of these 2 studies ${ }^{\mathrm{E} 6, \mathrm{E} 7}$ corrected for flow or used flow-independent formulas. Cohen and colleagues ${ }^{\mathrm{E} 15}$ compared 99 patients randomized to either a Toronto or Perimount valve by using effective orifice area by the continuity equation, which is relatively flow independent. Unlike our study's aim, their main aim was to compare regression of LV hypertrophy, the patients were randomized only after suitability was determined for both types of valve, and more than 1 surgeon implanted the valves. Nonetheless, effective orifice area and mean gradient were similar in both valves at 3 months and 1 year.

\section{Reasons for Differences}

Our results according to labeled size were similar to most of the literature for the Perimount ${ }^{\text {E15,E16 }}$ although they were better than results in studies ${ }^{\mathrm{E} 17}$ that used the modified Bernoulli equation studied at a delay after surgery. Our results for the Toronto were also similar to ${ }^{\mathrm{E} 15, \mathrm{E} 18}$ or better than ${ }^{\mathrm{E} 19}$ results in the literature.

Our results for the comparison of the 2 valve types need not be surprising. Although stentless porcine valves tend to be classed with homografts, the Toronto valve could be relatively obstructive compared with a normal native valve as a result of the thickness of the porcine root with its covering of Dacron, the muscle bar associated with the right coronary artery, and the modification of leaflet physiology as a result of preservation in glutaraldehyde. We also compared it with a bovine pericardial rather than a porcine stented valve. There is some evidence for better hemodynamic function in pericardial compared with porcine valves. ${ }^{\mathrm{E} 1, \mathrm{E} 20}$

Furthermore, comparisons may be affected by surgical methods, including suture techniques, the use of pledgets, the positioning of the valve relative to the annulus, the use of procedures to enlarge the aortic root, and the method of sizing. We did not need to enlarge the aorta, whereas others

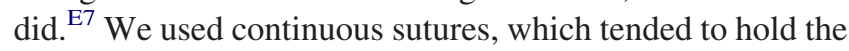
stented valve in a supra-annular position and enabled us to 
implant a larger valve than would be possible in an intraannular position. This difference in positioning is reflected by the fact that in our study the median labeled size was 24.7 for both the Toronto and Perimount. In other studies, the labeled size of the stentless valve was larger than that of the stented comparator valve: for example, 26.3 versus $22.9^{\mathrm{E} 15}$ or 26.3 versus 24.3 . $^{\mathrm{E} 2}$ The alternative explanation, that we undersized the Toronto, is unlikely because our labeled size was similar to that in these other studies. ${ }^{\text {E5-E7,E13-E15 }}$ Sizing for the Toronto valve was undertaken in all patients at the sinotubular junction as originally recommended by David and associates. ${ }^{\mathrm{E} 9}$ We did not enlarge the sinotubular junction in those patients in whom sizing at the annulus might have permitted implantation of a larger valve.

Comparisons may also be affected by the timing of the echocardiographic study after surgery. The aortic root swells around the stentless valve immediately after surgery, probably as a result of edema and hematoma. This swelling resolves and leads to an increase in the effective orifice area by approximately $0.2 \mathrm{~cm}^{2}$ or occasionally as much as 0.5 $\mathrm{cm}^{2}$ after 3 to 6 months, ${ }^{\text {E18,E21 }}$ although we, in common with others, ${ }^{\text {E15 }}$ showed no difference. In fact, an increase in valve area with time has also been shown for the Perimount valve, ${ }^{\mathrm{E} 15}$ thus suggesting that factors common to all types of valve, such as changes in flow, may be partly responsible.

\section{Regurgitation and Clinical Event}

Our study agrees with previous work ${ }^{\mathrm{E} 1, \mathrm{E} 22}$ in showing mild or moderate regurgitation through $10 \%$ of Toronto and $13.9 \%$ of Perimount valves at 1 year. By comparison, Dellgren and colleagues ${ }^{\mathrm{E} 16}$ showed mild regurgitation in $30 \%$ of Perimount valves at a mean of 67 months after surgery, and Banbury and colleagues ${ }^{\mathrm{E} 17}$ showed mild regurgitation in $19 \%$ and moderate regurgitation in $8 \%$ at 3 years. Similar degrees of regurgitation were reported in $9 \%$ to $21 \%^{\text {E18,E23-E25 }}$ of Toronto valves, whereas severe regurgitation was shown in $0.2 \%$. ${ }^{\text {224 }}$ Mild regurgitation is increasingly seen as the image quality and sensitivity of echocardiography systems improve and may be normal. Trivial regurgitation may even be seen on occasion in normal native valves. Although we are not aware of any evidence that such minor regurgitation has any clinical significance-for example, as a risk factor for endocarditis - no long-term confirmation of this exists. Furthermore, the incidence of regurgitation may increase with time in Toronto valves as a result of dilatation of the aortic root, ${ }^{\text {E26 }}$ although this was not found in the limited follow-up in this study. We found paraprosthetic regurgitation only in the Perimount, although in each case it was clinically unimportant.

There were no statistically significant differences between the Toronto and Perimount valves in clinical events or complications other than paraprosthetic regurgitation. This was true of the complete cohort at 1 year and the smaller number followed up to 5 years. There was no valve failure and no thrombosis or endocarditis. These results are similar to those of most previously reported studies. ${ }^{\mathrm{E} 16, \mathrm{E} 27, \mathrm{E} 28} \mathrm{In}$ the study of Desai and colleagues, ${ }^{\text {E29 }}$ there was 1 thrombosis of a Toronto valve 1 month after implantation, 1 failure of a Toronto at 23 months, and 12 failures at an average of 86 months, thus giving an actuarial freedom from structural failure of $98.8 \%$ at 5 years and $77.9 \%$ at 10 years.

The degree of regression of LV hypertrophy and measures of LV systolic function were no different at 3 to 6 months or 1 year for the 2 valve types. Other studies have shown no difference in LV mass regression ${ }^{\mathrm{E} 15, \mathrm{E} 27}$ or a benefit in favor of the Toronto or other stentless valve. ${ }^{\text {E6 }}$ This result is in keeping with the similarity in hemodynamic function between the 2 valves. However, there was limited regression of LV mass in both groups, with a mass index of $177 \mathrm{~g} / \mathrm{m}^{2}\left(\mathrm{SD}, 75 \mathrm{~g} / \mathrm{m}^{2}\right.$ ) for the Toronto and $182 \mathrm{~g} / \mathrm{m}^{2}$ (SD, $57 \mathrm{~g} / \mathrm{m}^{2}$ ) for the Perimount at 1 year. The factors determining LV mass regression are complex. The degree of regression depends less on replacement valve function than on the degree of preoperative hypertrophy, its duration before surgery, and the blood pressure after surgery. ${ }^{\text {E30 }}$

\section{Limitations}

There was complete follow-up for clinical events up to 1 year. However, numbers followed beyond 5 years were small. A small difference between the valves cannot therefore be excluded. The study continues, and fuller data in the mid-term and long-term will be reported. Randomization was performed at the start of operation, and there were 11 crossovers for technical reasons, usually because of extensive calcification or annular destruction. However, hemodynamic results were not materially affected, whether analysis was by intention-to-treat or actual valves implanted. There is increasing interest in the use of stentless valves as wholeroot replacements. This would be expected to improve the hemodynamic comparison against a stented valve, and our conclusions about the subcoronary Toronto might not apply to all stentless valves. It may often be inappropriate to compare stentless and stented valves as if these were uniform classes. It is clear that differences in performance may exist depending on constituent materials, the method of manufacturing, label sizes, and implantation techniques, and these differences need to be given in comparative studies.

\section{Conclusion}

This study showed no statistically significant difference in hemodynamic function, regression of LV hypertrophy, or clinical events at a year between the stentless porcine Toronto valve implanted in a subcoronary position and the stented bovine pericardial Perimount valve, which, in this study, was mounted in a supra-annular position. Paraprosthetic regurgitation was seen only for the Perimount valve. 


\section{E.References}

E1. Wang Z, Grainger N, Chambers J. Doppler echocardiography in normally functioning replacement heart valves: a literature review. J Heart Valve Dis. 1995;4:591-614.

E2. Jin XY, Zhang Z-M, Gibson DG, Yacoub MH, Pepper JR. Effects of valve substitute on changes in left ventricular function and hypertrophy after aortic valve replacement. Ann Thorac Surg. 1996;62:68390.

E3. David TE, Pollick C, Bos J. Aortic valve replacement with stentless porcine aortic bioprosthesis. J Thorac Cardiovasc Surg. 1990;99: 113-8.

E4. Cohen G, Christakis GT, Buth KJ, Joyner CD, Morgan CD, Sever JY, et al. Early experience with stentless versus stented valves. Circulation. 1997;96(suppl 2):II76-82.

E5. Nooten GV, Caes F, Francois K, Belleghem YV, Taeymans Y. Stentless or stented aortic valve implants in elderly patients? Eur J Cardiothorac Surg. 1999;15:31-6.

E6. Walther T, Langebartels G, Kruger M, Bernhardt U, Diegeler A, Gummert J, et al. Prospectively randomized evaluation of stentless versus conventional biological aortic valves. Circulation. 1999;100 (suppl 2):II6-10.

E7. Santini F, Bertolini P, Montalbano G, Vecchi B, Pessotto R, Prioli A, et al. Hancock versus stentless bioprostheses for aortic valve replacement in patients older than 75 years. Ann Thorac Surg. 1998;66:S99S103.

E8. Christakis GT, Buth KJ, Goldman BS, Fremes SE, Rao V, Cohan G, et al. Inaccurate and misleading valve sizing: a proposed standard for valve size nomenclature. Ann Thorac Surg. 1998;66:1198-2003.

E9. David TE, Feindel CM, Bos J, Sun Z, Scully HE, Rakowski H. Aortic valve replacement with a stentless porcine aortic valve. J Thorac Cardiovasc Surg. 1994;108:1030-6.

E10. Sahn DJ, De Maria A, Kisslo J, Weyman AE. The Committee on M-mode Standardization of the American Society of Echocardiography: recommendations regarding quantitation in M-mode echocardiography-results of a survey of echocardiographic measurements. Circulation. 1978;58:1072-81.

E11. Hammond IW, Devereux RB, Alderman MH, et al. The prevalence and correlates of echocardiographic left ventricular hypertrophy among employee patients with uncomplicated hypertension. J Am Coll Cardiol. 1988;7:639-50.

E12. Edmunds LH, Clark RE, Cohn LH, Grunkemeier GL, Miller DC, Weisel RD. Guidelines for reporting morbidity and mortality after cardiac valvular operations. J Thorac Cardiovasc Surg. 1996;112: 708-11.

E13. De Paulis R, Sommariva L, Colagrande L, De Matteis GM, Fratini F, Tomai F, et al. Regression of left ventricular hypertrophy after aortic valve replacement for aortic stenosis with different valve substitutes. J Thorac Cardiovasc Surg. 1998;116:590-8.

E14. Maselli D, Pizio R, Bruno LP, Di Bella I, De Gasparis C. Left ventricular mass reduction after aortic valve replacement: homografts, stentless and stented valves. Ann Thorac Surg. 1999;67: 966-71.

E15. Cohen G, Christakis GT, Joyner CD, Morgan CD, Tamariz M, Hanayama N, et al. Are stentless valves hemodynamically superior to stented valves? A prospective randomized trial. Ann Thorac Surg. 2002;73:767-78.

E16. Dellgren G, David TE, Raanani E, Armstrong S, Ivanov J, Rakowski H. Late hemodynamic and clinical outcomes of aortic valve replacement with the Carpentier-Edwards Perimount pericardial bioprosthesis. J Thorac Cardiovasc Surg. 2002;124:146-54

E17. Banbury MK, Cosgrove DM, Thomas JD, Blackstone EH, Rajeswaran J, Okies JE, et al. Hemodynamic stability during 17 years of the Carpentier-Edwards aortic pericardial bioprosthesis. Ann Thorac Surg. 2002;73:1460-5.

E18. Del Rizzo DF, Goldman BS, Christakis GT, David TE. Hemodynamic benefits of the Toronto stentless valve. J Thorac Cardiovasc Surg. 1996;112:1431-6.

E19. Mohr FW, Walther T, Baryalei M, Falk V, Autschbauch R, Scheidt A, et al. The Toronto SPV bioprosthesis: one-year results in 100 patients. Ann Thorac Surg. 1995;60:171-5.

E20. Walther T, Lehmann S, Falk V, Metz S, Doll N, Rastan A, et al. Prospectively randomized evaluation of stented xenograft hemodynamic function in the aortic position. Circulation. 2004;110(suppl 2):II74-8.

E21. Walther T, Autschbach R, Falk V, Baryalei M, Scheidt A, Dalichau $\mathrm{H}$, et al. The stentless Toronto SPV bioprosthesis for aortic valve replacement. Cardiovasc Surg. 1996;4:536-42.

E22. David TE. The Toronto SPV bioprosthesis: clinical and hemodynamic results at 6 years. Ann Thorac Surg. 1999;68:S9-13.

E23. David TE, Bos J, Rakowski H. Aortic valve replacement with the Toronto SPV bioprosthesis. J Heart Valve Dis. 1992;1:244-8.

E24. Bach DS, David T, Yacoub M, Pepper J, Goldman B, Wood J, et al. Hemodynamics and left ventricular mass regression following implantation of the Toronto SPV stentless porcine valve. Am J Cardiol. 1998;82:1214-9.

E25. Walther T, Falk V, Autschbach R, Scheidt A, Baryalei M, Schindewolf $\mathrm{K}$, et al. Hemodynamic assessment of the stentless Toronto SPVTM bioprosthesis by echocardiography. J Heart Valve Dis. 1994; 3:657-65.

E26. David TE, Ivanov J, Eriksson MJ, Bos J, Feindel CM, Rakowski H. Dilatation of sinotubular junction causes aortic insufficiency after aortic valve replacement with the Toronto SPV bioprosthesis. J Thorac Cardiovasc Surg. 2001;122:929-34.

E27. Doss M, Martens S, Wood JP, Aybek T, Kleine P, Greinecker GW, et al. Performance of stentless versus stented aortic valve bioprosthesis in the elderly patient: a prospective randomized trial. Eur J Cardiothorac Surg. 2003;23:299-304.

E28. Danton MH, Sarsam MA, Byrne JG, Campbell NS, Jones JM, Campalani G. Clinical and hemodynamic performance of the Toronto SPV bioprosthesis. J Heart Valve Dis. 2000;9:644-52.

E29. Desai ND, Merin O, Cohen GN, Herman J, Mobilos S, Sever JY, et al. Long-term results of aortic valve replacement with the St Jude Toronto stentless porcine valves. Ann Thorac Surg. 2004;78:207683

E30. Lund O, Erlendsen M, Dorup I, Emmertsen K, Flo C, Finn T. Predictable changes in left ventricular mass and function during ten years after valve replacement for aortic stenosis. J Heart Valve Dis. 2004; 13:357-68. 

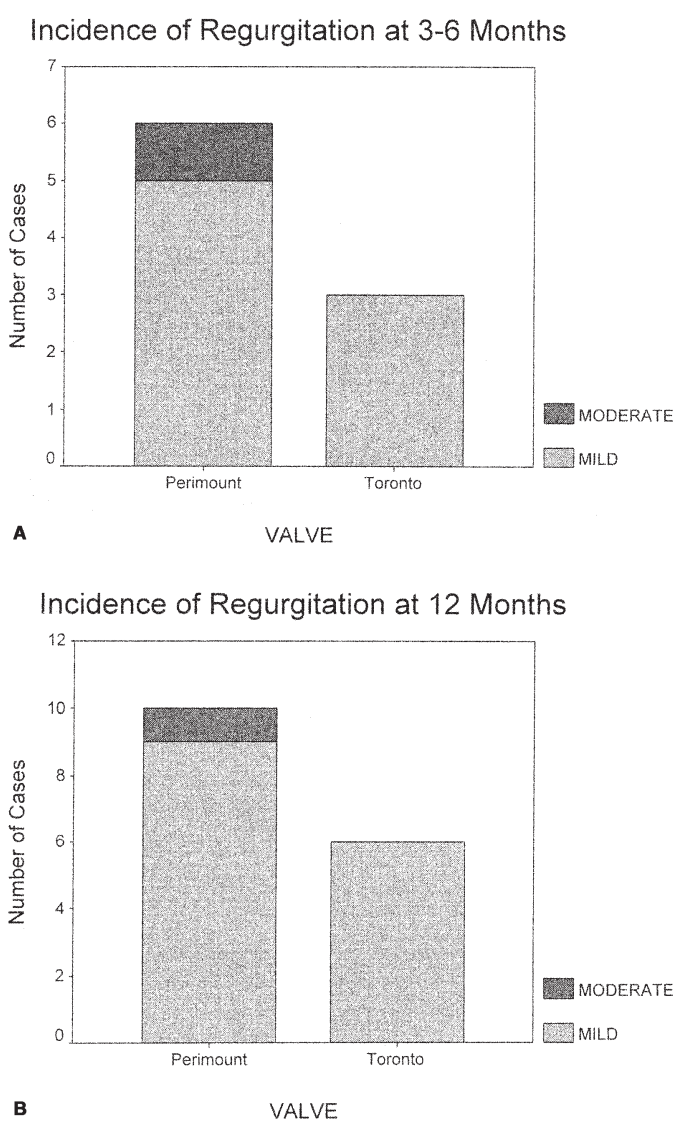

Figure E1. Incidence of transprosthetic regurgitation at (A) 3 to 6 months and (B) 1 year.

TABLE E1. Mean (SD) hemodynamic measures in the Toronto valve 3 to 6 months after surgery by labeled size

\begin{tabular}{lcccccc}
\hline & \multicolumn{5}{c}{ Labeled size $(\mathbf{n}=\mathbf{6 6})$} \\
\cline { 2 - 6 } Variable & $\mathbf{1 9}(\mathbf{n}=\mathbf{1})$ & $\mathbf{2 1}(\mathbf{n}=\mathbf{7})$ & $\mathbf{2 3}(\mathbf{n}=\mathbf{2 0})$ & $\mathbf{2 5}(\mathbf{n}=\mathbf{1 9})$ & $\mathbf{2 7}(\mathbf{n}=\mathbf{6})$ & $\mathbf{2 9}(\mathbf{n}=\mathbf{1 3})$ \\
\hline Aortic peak velocity $(\mathrm{m} / \mathrm{s})$ & 2.40 & $2.41(0.51)$ & $2.24(0.32)$ & $2.00(0.32)$ & $2.07(0.20)$ & $1.70(0.33)$ \\
Effective orifice area $\left(\mathrm{cm}^{2}\right)$ & 1.32 & $1.07(0.20)$ & $1.34(0.30)$ & $1.61(0.38)$ & $1.88(0.64)$ & $2.09(0.43)$ \\
Mean pressure difference $(\mathrm{mm} \mathrm{Hg})$ & 9.70 & $11.63(5.17)$ & $8.74(3.26)$ & $6.91(2.64)$ & $6.62(3.95)$ & $4.68(1.62)$
\end{tabular}

TABLE E2. Mean (SD) hemodynamic measures in the Perimount valve 3 to 6 months after surgery by labeled size

\begin{tabular}{llllll}
\hline & \multicolumn{4}{c}{ Labeled size $(\mathbf{n}=\mathbf{7 4})$} \\
\cline { 2 - 5 } Variable & $\mathbf{2 1} \mathbf{( n = 8 )}$ & $\mathbf{2 3}(\mathbf{n}=\mathbf{2 2})$ & $\mathbf{2 5}(\mathbf{n}=\mathbf{2 5})$ & $\mathbf{2 7}(\mathbf{n}=\mathbf{1 2})$ & $\mathbf{2 9}(\mathbf{n}=\mathbf{7})$ \\
\hline Aortic peak velocity $(\mathrm{m} / \mathrm{s})$ & $2.15(0.42)$ & $2.06(0.47)$ & $2.04(0.39)$ & $1.90(0.47)$ & $1.71(0.27)$ \\
Effective orifice area $\left(\mathrm{cm}^{2}\right)$ & $1.17(0.24)$ & $1.48(0.35)$ & $1.66(0.38)$ & $1.94(0.25)$ & $2.31(0.60)$ \\
Mean pressure difference $(\mathrm{mm} \mathrm{Hg})$ & $8.70(3.36)$ & $7.50(3.54)$ & $7.76(4.26)$ & $6.69(2.28)$ & $5.74(3.27)$ \\
\hline
\end{tabular}


TABLE E3. Mean (SD) hemodynamic measures in the Toronto valve 12 months after surgery by labeled size

\begin{tabular}{|c|c|c|c|c|c|c|}
\hline \multirow[b]{2}{*}{ Variable } & \multicolumn{6}{|c|}{ Labeled size $(n=60)$} \\
\hline & $19(n=1)$ & $21(n=6)$ & $23(n=20)$ & $25(n=19)$ & $27(n=5)$ & $29(n=9)$ \\
\hline Aortic peak velocity (m/s) & 2.50 & $2.42(0.48)$ & $2.27(0.35)$ & $2.03(0.33)$ & $2.04(0.38)$ & $1.62(0.18)$ \\
\hline Effective orifice area $\left(\mathrm{cm}^{2}\right)$ & 1.10 & $1.08(0.25)$ & $1.41(0.26)$ & $1.68(0.46)$ & $1.65(0.42)$ & $2.07(0.36)$ \\
\hline Mean pressure difference $(\mathrm{mm} \mathrm{Hg})$ & 10.4 & $10.92(6.55)$ & $8.95(2.95)$ & $7.03(2.94)$ & $8.38(3.03)$ & $4.39(1.27)$ \\
\hline
\end{tabular}

TABLE E4. Mean (SD) hemodynamic measures in the Perimount valve 12 months after surgery by labeled size

\begin{tabular}{llllll}
\hline & \multicolumn{4}{c}{ Labeled size $(\mathbf{n}=\mathbf{7 2})$} \\
\cline { 2 - 5 } Variable & $\mathbf{2 1} \mathbf{( n = 7 )}$ & $\mathbf{2 3}(\mathbf{n}=\mathbf{2 2})$ & $\mathbf{2 5}(\mathbf{n}=\mathbf{2 5})$ & $\mathbf{2 7}(\mathbf{n}=\mathbf{1 1})$ & $\mathbf{2 9}(\mathbf{n}=\mathbf{7})$ \\
\hline Aortic peak velocity $(\mathrm{m} / \mathrm{s})$ & $2.20(0.42)$ & $2.14(0.39)$ & $2.07(0.45)$ & $1.89(0.29)$ & $1.81(0.36)$ \\
Effective orifice area $\left(\mathrm{cm}^{2}\right)$ & $1.17(0.36)$ & $1.47(0.35)$ & $1.70(0.48)$ & $1.91(0.34)$ & $2.12(0.61)$ \\
Mean pressure difference $(\mathrm{mm} \mathrm{Hg})$ & $9.59(4.63)$ & $8.53(4.21)$ & $7.43(3.54)$ & $6.10(2.00)$ & $5.63(3.13)$ \\
\hline
\end{tabular}


TABLE E5. Clinical events: comparison of patients actually receiving Toronto or Perimount valves

\begin{tabular}{lcc}
\hline Variable & $\begin{array}{c}\text { Toronto } \\
\text { (n= 75) }\end{array}$ & $\begin{array}{c}\text { Perimount } \\
\text { (n = 85) }\end{array}$ \\
\hline Perioperative death & 0 & $1(1.2 \%)$ \\
Early death (before $30 \mathrm{~d})$ & $3(4.0 \%)$ & $3(3.5 \%)$ \\
Deaths $30 \mathrm{~d}$ to $12 \mathrm{mo}$ & $4(5.3 \%)$ & $2(2.4 \%)$ \\
Total deaths & $7(9.3 \%)$ & $6(7.1 \%)$ \\
All nonfatal complications (before $30 \mathrm{~d})$ & $4(5.3 \%)$ & $5(5.9 \%)$ \\
All nonfatal complications 30 d to $12 \mathrm{mo}$ & $5(6.7 \%)$ & $10(11.8 \%)$ \\
Total nonfatal complications & $9(12.0 \%)$ & $15(17.6 \%)$ \\
\hline
\end{tabular}

